\title{
Uma investigação sobre apropriação de resultados de matemática do Spaece: o caso da Escola Jabuti
}

Francisco Jucivanio Felix de Sousa*

Marco Aurélio Kistemann Jr.**

*(Instituto Federal do Ceará, Crateús, Ceará, Brasil)

**(Universidade Federal de Juiz de Fora, Juiz de Fora, Minas Gerais, Brasil)
Resumo: Este artigo investigou a situação do desempenho em matemática dos alunos do ensino médio da Escola Jabuti, pertencente à rede de ensino do estado do Ceará, a partir dos resultados do Spaece nos anos 2012 a 2014. Os objetivos definidos para este estudo foram investigar as ações de apropriação de resultados pelos gestores da escola e propor sugestões de ações para a situação analisada, visando a contribuir com a elaboração de uma proposta de intervenção para aprimorar o acompanhamento pedagógico e minimizar a defasagem de aprendizagem de matemática na referida escola. A questão que guiou a investigação foi: "Que ações de apropriação a gestão da escola tem mobilizado ante os resultados do Spaece?". Como produto final, foi elaborado um Plano de Ação Educacional (PAE) com possibilidades de melhorias nas práticas pedagógicas da escola e a aproximação de todos os membros da comunidade escolar.

Palavras-chave: Apropriação de resultados em matemática. Avaliação. Spaece. 


\section{INTRODUÇÃO}

Os resultados das avaliações externas são instrumentos relevantes para que gestores públicos e comunidades escolares verifiquem o desempenho dos alunos ao longo dos anos de escolarização, fornecendo feedback aos professores de sala de aula e ajudando na busca de soluções para superar as dificuldades de aprendizagem. A correta apropriação dos resultados, por exemplo, em matemática, auxilia no alcance de um dos objetivos centrais da escola, qual seja o de assegurar que as crianças, adolescentes, jovens e adultos efetivamente aprendam de forma significativa os conteúdos ensinados.

Os avanços referentes à possibilidade de obter o diagnóstico de desempenho dos alunos medidos por escola, nas disciplinas avaliadas, permitem que as avaliações externas, nos sistemas educacionais, sejam destinadas a produzir análises sobre a qualidade da educação oferecida pelas redes públicas de ensino, nas escalas federal, estadual ou municipal. Em 1992, com suporte no Decreto no 21.398/91 (CEARÁ, 1991), a Secretaria de Educação do Ceará criou o Sistema Permanente da Avaliação Básica do Ceará (Spaece), com o objetivo de fornecer informações qualificadas sobre a rede de ensino e promover e ações de melhoria na qualidade da educação cearense.

Os resultados dessa avaliação demonstraram uma realidade desanimadora no que se refere aos índices de proficiência relacionados ao ensino médio no Ceará, ao longo dos últimos anos, pois o estado apresentou resultados insatisfatórios nas disciplinas avaliadas (língua portuguesa e matemática). Conforme dados divulgados pelo Instituto Nacional de Estudos e Pesquisas Educacionais Anísio Teixeira (Inep), o Ceará não atingiu a meta do Índice de Desenvolvimento da Educação Básica ${ }^{1}$ (Ideb) em 2013 para o ensino médio. $\mathrm{Na}$ rede estadual, a nota caiu de 3,4 em 2011 para 3,3, sendo que a meta estabelecida era, à época, 3,5. Nesse sentido, esta pesquisa teve como objetivo investigar o desempenho discente nas avaliações externas, no caso específico do Spaece, numa unidade escolar, na qual o primeiro autor exerceu a função de coordenador escolar.

O Ideb foi criado pelo Inep em 2007, em uma escala de zero a dez. Sintetiza dois conceitos igualmente importantes para a qualidade da educação: aprovação e média de desempenho dos estudantes em língua portuguesa e matemática. 0 indicador é calculado a partir dos dados sobre aprovação escolar, obtidos no Censo Escolar, e médias de desempenho nas avaliações do Inep, Saeb e Prova Brasil. 
A Escola Jabuti investigada situa-se no município do Eusébio - CE, fazendo parte da Rede Estadual de Ensino e sob a abrangência da Coordenadoria Regional de Educação (Crede 01 - CE), composta por sete municípios localizados na Região Metropolitana de Fortaleza - Aquiraz, Caucaia, Eusébio, Guaiúba, Itaitinga, Maracanaú e Pacatuba. Boa parte dos estudantes possui baixo poder aquisitivo, sendo atendida pelos programas de geração de renda dispostos pelo governo federal. Nosso interesse por verificar e investigar como os dados das avaliações externas são divulgados para a comunidade educativa (professores, alunos, servidores e pais) em questão se justifica pelo fato de que a apropriação e o uso dos resultados das avaliações externas como meio pedagógico constituem um problema interessante para estudo.

De acordo com o último Boletim de Resultados do Spaece (2014), aproximadamente $75 \%$ dos alunos do 30 ano do ensino médio (EM) avaliados na escola em estudo estavam no nível "muito crítico" na disciplina de matemática. Outro ponto importante verificado foi que, nesse mesmo ano, somente $0,9 \%$ dos alunos do 3 a ano do EM da escola estava no nível adequado, ou seja, não atingindo nem 1\% do nível que seria considerado“adequado”.

Tais resultados revelaram que esses alunos não desenvolveram competências e habilidades mínimas, e estavam muito aquém do esperado para o período de escolarização. Para propor ações de intervenção e modificar a incômoda situação de baixa proficiência em matemática, buscamos nesta pesquisa responder à questão: "Que ações de apropriação a gestão da escola mobiliza ante os resultados do Spaece?” Como interrogações secundárias, a pesquisa ainda buscou compreender: "Que estratégias poderiam ser implantadas para se alcançar um resultado desejado?” E “O que deveria ser feito para a melhoria da qualidade de ensino na disciplina matemática?”.

O objetivo geral da pesquisa foi investigar as ações de apropriação de resultados realizadas pelos gestores da escola pesquisada e analisar o desempenho discente na disciplina matemática. Como objetivos específicos, nos propomos a investigar como ocorria o acompanhamento pedagógico relativo à apropriação dos resultados das avaliações externas e compreender a percepção que os agentes escolares (professores de matemática e o núcleo gestor da escola) tinham acerca da temática das avaliações de larga escala, bem como propor ações que possibilitassem em médio prazo a melhoria da qualidade de ensino na disciplina matemática na escola. 
Por dentro do Sistema Permanente de Avaliação da Educação Básica do Estado do CEARÁ (SPAECE)

A avaliação da educação básica do Ceará teve origem com as atividades de pesquisas educacionais institucionalizadas em 1961 com a criação da Diretoria de Pesquisas e Planejamento Educacional no interior da Secretaria de Educação do Estado do Ceará (Seduc) até 1991, recebendo variadas nomenclaturas, mas permanecendo sempre relacionada ao setor de planejamento da instituição (HIPPOLYTO, 2013). Conforme destaca Hippolyto (2013), ao longo de três décadas, de modo autônomo ou em parceria com a Universidade Federal do Ceará (UFC), a Fundação Carlos Chagas e o Inep/ MEC, a Seduc realizou um conjunto de investigações destinadas a conhecer a realidade educacional do Ceará, subsidiando os planos de intervenção voltados à resolução dos desafios e problemas.

Com efeito, no ano de 1992, pelo Decreto no 21.398/91 (CEARÁ, 1991), foi criado pelo governo do estado o sistema de avaliação do Ceará, chamado, inicialmente, de "Avaliação do Rendimento Escolar dos Alunos de $4^{\underline{a}}$ e $8^{\text {a }}$ Séries", passando a ser conhecido nos meios escolares como "Avaliação das Quartas e Oitavas”, e oficialmente, desde 1996, passou a ser utilizada a nomenclatura de Spaece (LIMA, 2007). No primeiro ano de avaliação, foram avaliados, de forma censitária, alunos de todas as escolas da rede estadual do município de Fortaleza - cerca de 14.600 -, com testes padronizados de português e matemática para a $4^{\underline{a}}$ e a $8^{\underline{a}}$ série do ensino fundamental. O Spaece, como sistema de avaliação, tinha como objetivos promover 0 conhecimento da qualidade da educação e produzir informações necessárias e suficientes para embasar a implementação, o monitoramento e a avaliação de políticas públicas voltadas para a área (CEARÁ, 2000).

Os resultados das avaliações divulgados nos boletins encaminhados às escolas possibilitavam aos docentes, diretores escolares e gestores acesso a um quadro sobre a situação do ensino fundamental e médio da rede pública de ensino, permitindo verificar as competências e habilidades dos alunos tanto em língua portuguesa quanto em matemática.

Por considerara importância da avaliação como instrumento eficaz de regulação da gestão e da aprendizagem, em 2007 a Seduc ampliou a abrangência do Spaece, incorporando a avaliação da alfabetização e expandindo a avaliação do ensino médio para as três séries, de maneira censitária. Assim, o Spaece passou a compreender a avaliação de leitura dos alunos do $2^{\circ}$ ano do ensino 
fundamental (Spaece-Alfa), o domínio das competências e das habilidades esperadas para as demais etapas de escolaridade, nas disciplinas língua portuguesa e matemática, para os alunos do $5^{\circ}$ e $9^{\circ}$ anos e nas turmas de $1^{\underline{a}}$, 2a e 3a séries do EM. As informações coletadas, a cada edição, identificam o nível de proficiência e a evolução do desempenho dos alunos do estado (CEARÁ, 2015).

Atualmente, a avaliação ocorre todo ano de modo universal, nos 184 municípios do estado, com a aplicação das provas nas redes estadual e municipal de ensino. Destaca-se o fato de que nesse sistema de avaliação, a análise dos dados não se centraliza somente no desempenho individual do aluno, mas também nas habilidades descritas na matriz de referência para avaliação. A Matriz de Referência do Spaece Matemática para o Ensino Médio abrange 76 descritores, agrupados nos quatro domínios citados há pouco. No Quadro 1, tem-se a estrutura do quadro de competências com seus respectivos descritores para o ensino médio.

Quadro 1 - Competências em matemática (ensino médio) - Spaece

\begin{tabular}{|c|c|c|c|c|}
\hline \multirow[t]{2}{*}{ DOMINIO } & \multirow[t]{2}{*}{ COMPETENCIAS } & \multicolumn{3}{|c|}{ DESCRITORES } \\
\hline & & $\begin{array}{l}\text { 1o Série do Ensino } \\
\text { Médio }\end{array}$ & $\begin{array}{l}2^{\circ} \text { Série do Ensino } \\
\text { Médio }\end{array}$ & $\begin{array}{l}3^{\circ} \text { Série do Ensino } \\
\text { Médio }\end{array}$ \\
\hline \multirow{4}{*}{$\begin{array}{l}\text { ESPAÇOE } \\
\text { FORMA }\end{array}$} & $\begin{array}{l}\text { Localizar objetos em representaçōes do } \\
\text { espaço. }\end{array}$ & D57 & • & D57 \\
\hline & $\begin{array}{l}\text { Identificar figuras geométricas e suas } \\
\text { propriedades. }\end{array}$ & • & D46 e D52. & D52 \\
\hline & Reconhecer transformações no plano. & $\cdot$ & $\cdot$ & $\cdot$ \\
\hline & Aplicar relações e propriedades. & D49 e D53 & D49, D50, D51 e D53. & $\begin{array}{l}\text { D49, D50, D51, D53, } \\
\text { D54, D55, D56 e D58. }\end{array}$ \\
\hline \multirow{3}{*}{$\begin{array}{l}\text { GRANDEZASE } \\
\text { MEDIDAS }\end{array}$} & Utilizar sistemas de medidas. & $\cdot$ & $\cdot$ & - \\
\hline & Medir grandezas. & D65 e D67. & D65, D67, D68 e D70. & D65, D67, D71 e D72. \\
\hline & Estimar e comparar grandezas. & • & D64 & D64 \\
\hline \multirow{3}{*}{$\begin{array}{l}\text { NÚMEROS, } \\
\text { OPERAÇŌES, } \\
\text { ALGEBRAE } \\
\text { FUNÇŌES }\end{array}$} & Conhecer e utilizar números. & D11, D16 e D22. & D16 e D22. & D16 \\
\hline & Realizar e aplicar operações. & D17 e D23. & D21 & D78 \\
\hline & Utilizar procedimentos algébricos. & $\begin{array}{l}\text { D18, D19, D28, D29, D30, } \\
\text { D31, D32, D 33, D34, D35, } \\
\text { D37, D39 e D44. }\end{array}$ & $\begin{array}{l}\text { D18, D28, D36, D38 e } \\
\text { D43. }\end{array}$ & $\begin{array}{l}\text { D19, D20, D24, D28 e } \\
\text { D40. }\end{array}$ \\
\hline \multirow{2}{*}{$\begin{array}{l}\text { TRATAMENTO } \\
\text { DA } \\
\text { INFORMAÇÃO }\end{array}$} & $\begin{array}{l}\text { Ler, utilizar e interpretar informações } \\
\text { apresentadas em tabelas e gráficos. }\end{array}$ & D75 e D76. & D75 e D76. & D76 \\
\hline & $\begin{array}{l}\text { Utilizar procedimentos de combinatória e } \\
\text { probabilidade. }\end{array}$ & • & D41 e D42. & D42 \\
\hline
\end{tabular}

Fonte: Ceará (2015).

Os descritores são elencados em seguida no Quadro 2, com as respectivas competências que precisam ser desenvolvidas no ensino médio em matemática. Esses descritores são agrupados nos quatro Domínios, elencados no Quadro 1. 
Quadro 2 - Descritores em matemática, do ensino médio, na avaliação do Spaece

D11 Ordenar ou identificar a localização de números racionais na reta numérica.

D16 Estabelecer relações entre representações fracionárias e decimais dos números racionais.

D17 Resolver situação-problema utilizando porcentagem.

D18 Resolver situação-problema envolvendo a variação proporcional entre grandezas direta ou inversamente proporcionais.

D19 Resolver problema envolvendo juros simples.

D20 Resolver problema envolvendo juros compostos.

D21 Efetuar cálculos com números irracionais, utilizando suas propriedades.

D22 Identificar a localização de números reais na reta numérica.

D23 Resolver situação-problema com números reais envolvendo suas operações.

D28 Reconhecer a representação algébrica ou gráfica da função polinomial de $1^{\mathfrak{0}}$ grau.

D29 Resolver situação-problema envolvendo função polinomial do $1^{\circ}$ grau.

D30 Reconhecer a representação algébrica ou gráfica da função polinomial de $2^{\circ}$ grau.

D31 Resolver situação-problema envolvendo função quadrática.

D32 Resolver situação-problema que envolva os pontos de máximo ou de mínimo no gráfico de uma função polinomial do $2^{\circ}$ grau.

D33 Reconhecer a representação algébrica ou gráfica da função exponencial.

D34 Resolver situação-problema envolvendo função exponencial.

D35 Reconhecer a representação algébrica ou gráfica da função logarítmica.

D36 Reconhecer a representação gráfica das funções trigonométricas (seno, cosseno e tangente).

D37 Resolver situação-problema envolvendo inequações do $1^{\circ}$ ou $2^{\circ}$ graus.

D38 Resolver situação-problema envolvendo sistema de equações lineares.

D39 Resolver situação-problema envolvendo propriedades de uma progressão aritmética ou geométrica (termo geral ou soma).

D40 Relacionar as raízes de um polinômio com sua decomposição em fatores do $1^{0}$ grau.

D41 Resolver problemas de contagem utilizando o princípio multiplicativo ou noções de permutação simples, ou combinação simples.

D42 Resolver situação-problema envolvendo o cálculo da probabilidade de um evento.

D43 Determinar, no ciclo trigonométrico, os valores de seno e cosseno de um arco no intervalo $[0,2 \pi]$.

D46 Identificar o número de faces, arestas e vértices de figuras geométricas tridimensionais representadas por desenhos.

D49 Resolver problemas envolvendo semelhança de figuras planas.

D50 Resolver situação-problema aplicando o Teorema de Pitágoras ou as demais relações

métricas no triângulo retângulo.

D51 Resolver problemas usando as propriedades dos polígonos (soma dos ângulos internos, número de diagonais e cálculo do ângulo interno de polígonos regulares). 
D52 Identificar planificações de alguns poliedros e/ou corpos redondos.

D53 Resolver situação-problema envolvendo as razões trigonométricas no triângulo retângulo (seno, cosseno, tangente).

D54 Calcular a área de um triângulo pelas coordenadas de seus vértices.

D55 Determinar uma equação da reta a partir de dois pontos dados ou de um ponto e sua inclinação.

D56 Reconhecer, dentre as equações do $2^{\circ}$ grau com duas incógnitas, as que representam circunferências.

D57 Identificar a localização de pontos no plano cartesiano.

D58 Interpretar geometricamente os coeficientes da equação de uma reta.

D64 Resolver problema utilizando as relações entre diferentes unidades de medidas de capacidade e de volume.

D65 Calcular o perímetro de figuras planas numa situação-problema.

D67 Resolver problema envolvendo o cálculo de área de figuras planas.

D68 Resolver problemas envolvendo cálculo de área da superfície, lateral ou total, de prismas.

D70 Resolver problemas envolvendo cálculo de volume de prismas.

D71 Calcular a área da superfície total de prismas, pirâmides, cones, cilindros e esfera.

D72 Calcular o volume de prismas, pirâmides, cilindros e cones em situação-problema.

D75 Resolver problema envolvendo informações apresentadas em tabelas ou gráficos.

D76 Associar informações apresentadas em listas e/ou tabelas aos gráficos que as representam, e vice- versa.

D78 Resolver problemas envolvendo medidas de tendência central: média, moda ou mediana.

Fonte: Ceará (2015).

Destacamos que as informações extraídas da avaliação podem identificar o nível de proficiência e a evolução do desempenho dos alunos, mensurados pelos padrões de desempenho. Com referência à escala de proficiência adotada pelo Spaece, pode-se considerar que ela representa a medida de uma grandeza. Essa escala estipula um intervalo contínuo de valores que representam o desempenho em dada disciplina. Essa interpretação da escala possibilita relacionar medidas de proficiência com diagnósticos qualitativos do desempenho escolar. Nessa Escala de Proficiência, os resultados da avaliação encontram-se em níveis, revelando o desempenho dos alunos do mais baixo ao mais elevado. A escala varia de 0 a 500 pontos, de modo a conter, em uma mesma "régua", a distribuição dos resultados do desempenho dos alunos no período de escolaridade avaliado. Esses intervalos são os níveis de proficiência (CEARÁ, 2015). 
Na Escala de Proficiência, foram definidas categorias com suporte em cortes numéricos que agrupam os níveis da Escala de Proficiência, com base nas metas educacionais estabelecidas pelo Spaece tanto para português como matemática. Esses cortes dão origem a quatro padrões de desempenho: Muito crítico, Crítico, Intermediário e Adequado, os quais denotam o desempenho dos alunos. Esses padrões ainda descrevem, sinteticamente, as características comuns a alunos num mesmo nível de proficiência e, portanto, tomam como referência o desempenho nos testes, ou seja, as habilidades que eles demonstraram ter desenvolvido.

Na Figura 1, explicitamos a Escala de Proficiência em matemática do ensino médio nas avaliações do Spaece:

Figura 1 - Escala de proficiência em matemática, do ensino médio, na avaliação do Spaece

\begin{tabular}{|c|l|l|l|l|l|l|l|l|l|l|l|l|l|l|l|l|l|l|l|l|l|}
\hline $\begin{array}{c}\text { Padrão de } \\
\text { Desempenho }\end{array}$ & 0 & 25 & 50 & 75 & 100 & 125 & 150 & 175 & 200 & 225 & 250 & 275 & 300 & 325 & 350 & 375 & 400 & 425 & 450 & 475 & 500 \\
\hline Muito Crítico & & & & & & & & & & & & & & & & & & & \\
\hline Crítico & & & & & & & & & & & & & & & & & & & & \\
\hline Intermediário & & & & & & & & & & & & & & & & & & & & \\
\hline Adequado & & & & & & & & & & & & & & & & & & & \\
\hline
\end{tabular}

Fonte: Elaborado pelos autores com base nos dados do Spaece (2015).

Assim, alunos de um padrão de desempenho considerado muito crítico ou crítico para sua etapa de escolaridade necessitam de atenção e de ações pedagógicas especializadas, de modo a garantir o desenvolvimento das habilidades necessárias ao sucesso escolar, evitando a repetência e/ou evasão.

A caracterização do padrão de desempenho em matemática no Spaece com o nível de proficiência torna possível uma interpretação do desempenho dos alunos, facultando aos gestores e professores poderem identificar problemas na aquisição do conhecimento por esses alunos e promover ações para elevar o nível de entendimento desenvolvido pelos agentes nos processos de ensino e aprendizagem.

É perceptível, pela Tabela 1, o fato de que o nível de aprendizagem não é satisfatório. Observamos que em matemática os alunos do $1^{0}$ ano do ensino médio exprimem sérias defasagens na aprendizagem. Verifica-se ainda no recorte de tempo considerado que tanto a Crede 01 quanto a escola 
estiveram abaixo do desempenho do estado, onde os alunos avaliados foram considerados com nível de proficiência "muito crítico".

Tabela 1 - Dados do Spaece (2012 a 2014 - ensino médio) - Resultados de desempenho em matemática

\begin{tabular}{|c|c|c|c|c|c|c|c|c|c|}
\hline & \multicolumn{3}{|c|}{2012} & \multicolumn{3}{|c|}{2013} & \multicolumn{3}{|c|}{2014} \\
\hline & $1^{\circ}$ Ano & $2^{\circ}$ Ano & $3^{\circ}$ Ano & $1^{\circ}$ Ano & $2^{\circ}$ Ano & $3^{\circ}$ Ano & $1^{\circ}$ Ano & $2^{\circ}$ Ano & $3^{\circ} \mathrm{Ano}$ \\
\hline Ceará & 251,4 & 260,1 & 260,7 & 249,9 & 257,3 & 267,8 & 253,1 & 257,4 & 266,3 \\
\hline Crede & 246,8 & 254,1 & 252,8 & 247,4 & 251,8 & 263,8 & 247,9 & 249,5 & 260,1 \\
\hline Escola & 220,5 & 237,8 & 244,7 & 223,3 & 231,1 & 257,3 & 219,9 & 213,9 & 230,3 \\
\hline
\end{tabular}

Fonte: Elaborado pelos autores com base em dados do Spaece (2015).

Os dados revelam que o Sistema Educacional do Estado do Ceará tem conseguido avançar de modo muito lento, perante uma escala que varia de $0 \mathrm{a}$ 500. Porém, deve-se considerar que, embora tenha sido um avanço pequeno, esse crescimento é relevante mediante o cenário da educação brasileira, que apresenta um resultado de desempenho decrescente no ensino médio nos últimos anos. Isso demonstra ser necessário um cuidado maior com as políticas educacionais para o ensino médio, pois os alunos apresentam sérias dificuldades em desenvolver habilidades de língua portuguesa e de matemática, previstas nas séries estipuladas para essa modalidade.

O CAMPO DA PESQUISA: A ESCOLA JABUTI

A pesquisa se desenvolveu na Escola Jabuti, situada no distrito do Jabuti, no município de Eusébio, região metropolitana de Fortaleza. Esse bairro limitase com as comunidades dos distritos de Pedra/Santo Antônio, Cidade Nova, faz divisa com o município de Itaitinga e localiza-se às margens da BR-116, considerado um bairro de periferia. Possui boa infraestrutura, como água encanada, coleta de lixo, asfalto em algumas ruas, energia elétrica, transporte coletivo, creches, escolas municipais e estaduais.

Aopção por essa escola como campo de pesquisa deu-se pelo fato de o primeiro autor ter sido coordenador da instituição durante o início da pesquisa, o que facilitou o acesso aos dados necessários e aos sujeitos da pesquisa, além de poder contribuir para a implantação de melhorias na instituição de ensino. $\mathrm{Na}$ época da pesquisa, a Escola Jabuti possuía 675 alunos, distribuídos nas três séries do ensino médio, contando com 32 professores, sendo 16 efetivos e 16 em caráter temporário, nos turnos da manhã, tarde e noite. 
Todos os docentes possuem nível superior e, na área administrativa, havia seis funcionários, sendo dois agentes administrativos, dois porteiros e duas merendeiras. O núcleo gestor estava sob a coordenação de um diretor escolar e três coordenadores escolares. A escola também contava com professores coordenadores de área nas três áreas (Linguagens e Códigos, Ciências Humanas e Ciências da Natureza).

0 desempenho dos alunos da escola em matemática no Spaece

Os dados relativos ao percentual de alunos na disciplina matemática no Ceará demonstraram que, apesar de um pequeno avanço no padrão de desempenho adequado nos anos considerados, houve piora no padrão de desempenho nos níveis muito crítico e crítico. Houve um acréscimo de 2,8\% do ano de 2013 para 2014 nesses padrões de desempenho, dos alunos do $3^{\circ}$ ano do EM que participaram do Spaece no estado do Ceará em 2014, conforme revelado na Tabela 2.

Tabela 2 - Percentual de alunos da rede estadual do Ceará por nível de proficiência, em matemática, no ensino médio, na avaliação do Spaece (2012-2014)

\begin{tabular}{|c|c|c|c|c|}
\hline & Muito Crítico & Crítico & Intermediário & Adequado \\
\hline 2012 & 47,8 & 29,2 & 16,4 & 6,6 \\
\hline 2013 & 39,7 & 34,0 & 18,4 & 7,9 \\
\hline 2014 & 42,2 & 33,6 & 16,0 & 8,1 \\
\hline
\end{tabular}

Fonte: Elaborado pelos autores com base em dados do Spaece (2015).

A Escola Jabuti, objeto da nossa pesquisa, também fez parte dessa estatística. Os resultados da proficiência de 2014 no ensino médio, em matemática, apontaram que $96,0 \%$ dos alunos se enquadram nas faixas referidas (com $74,6 \%$ "muito crítico" e 21,4\% “crítico"), conforme se observa na Tabela 3.

Tabela 3 - Percentual de alunos por nível de proficiência e padrão de desempenho, em matemática, no $3^{0}$ ano do EM, na avaliação do Spaece

\begin{tabular}{|c|c|c|c|c|}
\hline & Muito Crítico & Crítico & Intermediário & Adequado \\
\hline 2012 & 62,0 & 25,6 & 8,5 & 3,9 \\
\hline 2013 & 47,9 & 25,1 & 27,0 & 0,0 \\
\hline 2014 & 74,6 & 21,4 & 3,2 & 0,9 \\
\hline
\end{tabular}

Fonte: Elaborado pelos autores com base em dados do Spaece (2015). 
Ao fazermos uma comparação entre os anos de 2012 e 2014, a escola não exibiu evolução satisfatória no desempenho dos discentes avaliados. Em 2012, concentrava $62,0 \%$ dos alunos no nível muito crítico, baixou para 47,9\% no ano seguinte, porém, em 2014, esse nível concentrou sozinho quase três quartos (3/4) da população de alunos da escola, ou seja, 74,6\%. Um ponto interessante foi que no ano de 2013 houve uma concentração de alunos no nível intermediário de aprendizagem, 27\%. Segundo o coordenador da escola, nesse ano não houve ausência de professores de matemática durante o período letivo. Os alunos tiveram aulas regularmente durante todo 0 ano letivo e, nesse mesmo período, as provas para o $2^{\circ}$ e o 3 anos do $E M$ passaram a ser por amostragem.

Ao analisarmos o nível de padrão de desempenho que seria considerado adequado para a Escola Jabuti, verificou-se variação negativa durante o ano de 2012 para 2013, quando nenhum aluno estava nesse nível de aprendizagem. Ainda para o ano de 2014, ocorreu uma melhora mínima, pois se conseguiu obter $0,9 \%$ dos alunos no nível adequado, mas não atingindo o 1\% do nível que seria apropriado para esses discentes do ensino médio regular.

Ao considerarmos as habilidades matemáticas características do padrão “muito crítico", de acordo com o Boletim do Spaece da rede estadual do Ceará (2015, p. 42), para o ensino médio, em matemática, tem-se que

\section{[...] nesse padrão de desempenho, as habilidades matemáticas que se evidenciam são as relativas aos significados dos números nos diversos contextos sociais. Os alunos demonstram compreender o uso do algoritmo da adição de números de até três algarismos com reagrupamento, da subtração de números naturais de até quatro algarismos com reserva, da divisão exata por números de até dois algarismos e da multiplicação cujos fatores também são números de até dois algarismos (CEARÁ, 2015, p. 42).}

O problema da defasagem de aprendizagem em matemática na Escola Jabuti

Ao verificar os indicadores educacionais da Escola Jabuti, como taxas de aprovação, reprovação, abandono e evasão, foram constatadas elevadas taxas de abandono e o aumento na taxa reprovação no ano de 2014 . É possível notar que um dos grandes desafios a ser superado pela escola era a garantia de uma aprendizagem satisfatória para os discentes, possibilitando um aumento no nível de conhecimento e o domínio do conteúdo curricular estudado por eles.

Além disso, com base nos dados da última edição do Spaece (2014), identificamos o fato de que aproximadamente $75 \%$ dos estudantes do ensino médio da escola estão com padrão de proficiência “muito crítico”, na 
disciplina matemática, sendo possível inferir que a maioria dos alunos denota dificuldades de aprendizado, fator que influencia a qualidade do ensino a ser ofertado pela escola.

Outro dado importante está nas taxas de distorção idade-série, pois com taxas de reprovação e de repetência elevadas, o desempenho da aprendizagem será um ponto problemático que afetará diretamente a qualidade de ensino que a escola oferta, conforme mostramos na Tabela 4, que traz a distorção idade-série no ensino médio:

Tabela 4 - Distorção idade-série no ensino médio por série e redes de ensino total (\%) - por rede de ensino e períodos selecionados

\begin{tabular}{|c|c|c|c|c|c|c|c|c|c|c|c|c|}
\hline & & \multicolumn{3}{|c|}{2012} & & \multicolumn{3}{|c|}{2013} & & \multicolumn{3}{|c|}{2014} \\
\hline & M & $1^{\circ} \mathrm{Ano}$ & $2^{\circ} \mathrm{Ano}$ & $3^{\circ}$ Ano & M & $1^{\circ} \mathrm{Ano}$ & $2^{\circ}$ Ano & $3^{\circ} \mathrm{Ano}$ & M & $1^{\circ} \mathrm{Ano}$ & $2^{\circ}$ Ano & $3^{\circ} \mathrm{Ano}$ \\
\hline Ceará & 31,1 & 34,6 & 29,8 & 27,5 & 30,3 & 33,7 & 29,6 & 26,2 & 31,7 & 35,1 & 31,2 & 27,2 \\
\hline Eusébio & 29,5 & 31,4 & 30,3 & 25,4 & 28,7 & 32,6 & 25,6 & 25,3 & 28,7 & 32,6 & 25,6 & 25,3 \\
\hline Escola & 36,7 & 39 & 38,5 & 31,3 & 38 & 37,7 & 36 & 41,3 & 33,9 & 37,3 & 29.3 & 34,4 \\
\hline
\end{tabular}

Fonte: Elaborado pelos autores com base em dados do Inesp (2016).

A distorção idade-série nessa escola é elevada, pois, considerando os três anos de recorte da amostra, 2012 a 2014, a instituição foi a que apontou o maior índice durante o período considerado, se comparados ao município onde se localiza e ao estado do Ceará. É possível verificar, nos dados da Tabela 5, que os alunos da $1^{\underline{a}}$ série do EM de 2012, que estavam concluindo a $3^{\underline{a}}$ série em 2014, permaneceram praticamente no mesmo nível de proficiência. Em 2012, 75,6\% se encontravam no nível "muito crítico", e, dois anos depois, estavam com $74,6 \%$. Houve aumento na porcentagem do nível muito crítico de $19,5 \%$, em 2012, para $21,4 \%$, em 2014. No nível de proficiência adequado, houve pequena evolução quando os alunos saíram da porcentagem $0 \% \mathrm{em}$ 2012 para 0,9\% em 2014. 
Tabela 5 - Nível de proficiência dos alunos da Escola Jabuti - Desempenho em matemática por série

\begin{tabular}{|c|c|c|c|c|}
\hline \multirow[t]{2}{*}{ SÉRIE } & \multirow{2}{*}{$\begin{array}{c}\text { NÍVEL DE } \\
\text { PROFICIÊNCIA }\end{array}$} & \multicolumn{3}{|c|}{ DISCIPLINA DE MATEMÁTICA } \\
\hline & & 2012 & 2013 & 2014 \\
\hline \multirow{4}{*}{$1 \stackrel{0}{A}$ Ano } & Muito Crítico & 75,6 & 73,7 & 76,1 \\
\hline & Crítico & 19,5 & 22,2 & 20 \\
\hline & Intermediário & 5 & 3,5 & 3,9 \\
\hline & Adequado & 0 & 0,4 & 0 \\
\hline \multirow{4}{*}{$2^{\circ}$ Ano } & Muito Crítico & 62,8 & 66,6 & 81,3 \\
\hline & Crítico & 27,2 & 29,1 & 14,7 \\
\hline & Intermediário & 10,1 & 4,4 & 4,1 \\
\hline & Adequado & 0 & 0 & 0 \\
\hline \multirow{4}{*}{ 3ำ Ano } & Muito Crítico & 62 & 47,9 & 74,6 \\
\hline & Crítico & 25,6 & 25,1 & 21,4 \\
\hline & Intermediário & 8,5 & 27 & 3,2 \\
\hline & Adequado & 3,9 & 0 & 0,9 \\
\hline
\end{tabular}

Fonte: Elaborado pelos autores com base em dados do Spaece (2015).

0 que fazer com os dados apresentados? Fundamentando um estudo de caso

Para responder a nossa pergunta diretriz e atingir os objetivos citados anteriormente realizamos um estudo de caso na Escola Jabuti. Conforme preconizam Gil (2008) e Yin (2001), o estudo de caso possibilita a investigação profunda de uma organização com o objetivo de testar a validade das hipóteses ou questões de pesquisas constituídas com suporte em um referencial teórico.

Para esta investigação, definimos os autores Alavarse, Blasis e Falsarella (2013), Freitas (2014), Lück (2000, 2009), Miranda e Dusi (2014), Silva (2014), Sousa e Oliveira (2010), Machado (2012) e Vieira (2007), que abordam questões como apropriação de resultados, autonomia escolar e responsabilização, devendo ser entendidas dentro da gestão da escola, onde todos os atores escolares precisam estar envolvidos nessa tomada de decisão para a melhora do desempenho acadêmico dos alunos e da prática pedagógica dos professores. Também nos embasamos em autores da educação matemática como Brito Menezes (2006), Canuto (2013), D’Ambrosio (2009), Lorenzato (2006), Muniz (2010) e Rocha (2014), que teorizam acerca de a importância interativa professor-aluno-conhecimento estar atrelada às práticas pedagógicas contextualizadas. 
Nossa pesquisa consistiu em um estudo de natureza qualitativa, pois, conforme Bastos e Keller (2007), esse tipo de investigação se caracteriza como subjetiva, usada em população pequena, cujo critério não é numérico. Caracteriza-se ainda como estudo de caso, pois a vivência e a convivência do pesquisador com os atores sociais envolvidos no estudo foram importantes para a descrição e reflexão dos saberes e processos da gestão escolar estudados, fazendo conexão entre os aspectos do desempenho escolar, da gestão e os aspectos da apropriação dos resultados na disciplina matemática.

A pesquisa privilegiou as seguintes etapas: a) Pesquisa bibliográfica e documental dos dados secundários existentes e de estudos correlatos; b) Pesquisa de campo na escola investigada, e c) Análise e reflexão dos saberes emergentes dos dados coletados. 0 instrumento de pesquisa utilizado foi a entrevista semiestruturada, realizada com os seguintes sujeitos da pesquisa: dois professores da disciplina matemática e três integrantes do núcleo gestor (um diretor e dois coordenadores escolares) da escola pesquisada.

As questões da entrevista foram elaboradas com base no modelo de questões utilizadas na entrevista e questionários desenvolvidos em Rocha (2014) para o corpo docente e discente em uma instituição de ensino, com o objetivo de analisar o baixo desempenho em matemática dos alunos na referida organização escolar.

A equipe gestora da instituição era composta por um diretor geral e três coordenadores escolares. Os docentes de matemática da escola compunham um grupo formado por quatro professores, todos licenciados em Matemática e com vínculo efetivo com a Secretaria de Educação do Estado do Ceará. Foram entrevistados o diretor da escola, um coordenador escolar, que participava da gestão da escola desde o ano de 2010, e outra coordenadora que estava na escola desde 2014. Foram selecionados os dois professores que, além de estarem há mais tempo na escola, possuíam 40 horas de trabalho semanal na instituição e desempenhavam suas atividades durante os três turnos de ensino.

As questões das entrevistas foram elaboradas visando à análise da gestão escolar em suas vertentes pedagógicas, com o intuito de identificar como é realizada a apropriação dos resultados das avaliações externas, como os coordenadores acompanham as práticas pedagógicas da escola, como as práticas docentes influenciam a aprendizagem matemática e como essas práticas são realizadas, tentando verificar qual a possível justificativa para 0 
baixo rendimento dos discentes da instituição em matemática nas avaliações em larga escala do Spaece.

A coleta de dados foi efetivada por meio de observações feitas, bem como foram efetuadas anotações acerca do cotidiano escolar em caderno de campo, análise documental de dados secundários relacionados ao tema da pesquisa, como o projeto político-pedagógico (PPP) da escola e os resultados do censo escolar, além da realização da entrevista. No dia 17 de março de 2016 foram realizadas as quatro entrevistas: a primeira com o diretor, depois com os dois coordenadores escolares e, por fim, com um professor de matemática da escola.

Todos os entrevistados eram efetivos da Secretaria de Educação do Estado do Ceará, com licenciaturas plenas e especialização nas respectivas áreas de formação. A composição dos entrevistados por gênero ficou definida em três homens e duas mulheres. As entrevistas tiveram duração média de 30 minutos, destacando-se que a entrevista com maior duração foi com o gestor escolar, que durou 45 minutos.

ANÁlISE DOS DADOS: A VOZ DOS SUJEITOS DA PESQUISA E NOSSAS LEITURAS

A análise dos dados refere-se ao primeiro eixo da entrevista, no qual buscamos identificar se a gestão escolar desenvolve uma cultura de apropriação dos resultados das avaliações externas do Spaece e investigar as orientações da equipe gestora sobre os resultados, e quais ações na escola existem para discutir esses resultados. Essas questões foram elaboradas para todos os agentes escolares entrevistados, objetivando constatar similaridades ou possíveis pontos divergentes entre a gestão escolar e o corpo docente da escola, fazendo um comparativo entre os distintos pontos de vistas dos entrevistados.

Dos pontos levantados pelo diretor da unidade escolar, destacam-se os seguintes: alta rotatividade de professores; ausência do gestor no período de 2014 por motivo de saúde; coordenadores sobrecarregados pela parte administrativa, quanto à parte da apropriação dos resultados. Dos comentários do coordenador, C1, podemos expor que, no período de 2010-2013, a divulgação dos resultados acontecia mais efetivamente com os professores e os alunos. Já na gestão de 2014-2016, pelos motivos expostos (carência de professores, afastamento do gestor e com isso o excesso de trabalho 
burocrático, planejamentos escolares diferenciados entre sede e anexo da escola), o trabalho de "apresentação" dos dados para a comunidade escolar ficou mais distante da realidade da escola.

Nas falas do gestor escolar e do coordenador revela-se o que pode ter influenciado o gerenciamento dos resultados que a escola vem apresentando nos últimos anos, como: a carência e a alta rotatividade de professores; a infraestrutura da escola, que não possibilitava que os encontros pedagógicos fossem unificados; e coordenadores escolares que precisaram acumular 0 trabalho que deveria ser realizado pelo gestor, já que este ficou de licença. De acordo com Lück (2009), cabe à gestão escolar (diretor e coordenadores escolares) fortalecer o papel da escola em promover a aprendizagem e formação dos seus alunos, além de compreender os mecanismos da avaliação de resultados educacionais, pois se constitui uma das condições fundamentais para definir qualificações que tornam as escolas mais eficazes. Diante dos problemas apontados, esse fortalecimento ficou comprometido.

Esse mesmo questionamento foi feito ao professor P1, que na entrevista relatou que

A escola faz uma reunião com os professores e com toda a equipe da escola, acontecendo essas reuniões no início de cada ano letivo, e quando está próximo da realização das próximas avaliações. Participam dessas reuniões professores, coordenadores e o diretor da instituição. Para os alunos, o professor repassa os índices obtidos para os alunos em suas aulas, observando onde eles foram bem, onde foram péssimos (P1. Entrevista concedida em

Já o professor P2 informou que "na escola em que ensino, os índices são apenas expostos no dia em que sai o resultado e isso é anualmente", sem explicar como essa exposição acontece na instituição de ensino. Ao realizarmos uma análise das falas dos entrevistados, percebemos que a escola busca divulgar os resultados das avaliações do Spaece basicamente no início do ano de cada período letivo seguinte à realização das provas. Essa divulgação é proposta às vezes individualmente e, quando acontece coletivamente, é nas reuniões pedagógicas, de que todos os professores da escola participam.

Inferimos, pela fala do diretor escolar e dos coordenadores, que a escola enfrenta sérios problemas quanto ao processo de carência de professores, falta de um planejamento coletivo para todas as áreas, pois a escola é dividida em sede e um anexo. Percebemos também que alguns atores escolares 
(servidores e pais) não são informados sobre os resultados da avaliação. Segundo informações coletadas nas entrevistas, apenas os alunos recebem os resultados por meio de exposição em sala dos resultados pelo gestor e/ou professor, P1, que se disponibilizam a informar os alunos como eles estão no processo de desempenho escolar na disciplina matemática no Spaece.

Quando perguntamos sobre como acontecem os processos de apropriação dos resultados do Spaece na escola, foram dadas as seguintes respostas:

\begin{abstract}
Com os dados em mãos é feita uma análise junto ao corpo docente sobre em quais descritores os alunos têm maior índice de acertos ou erros para direcionar o trabalho em sala de aula, fazendo com que as dificuldades sejam superadas e fortalecendo as competências já adquiridas. No início do ano, os professores, com o apoio da gestão pedagógica, realizam avaliação diagnóstica com o objetivo de nivelar as competências necessárias de serem alcançadas para cada série. Temos um olhar diferenciado aos alunos da $1^{a}$ série, oriundos do ensino fundamental, que passam a ser nossos educandos para nos apropriarmos do processo de aprendizagem dessa clientela (C2. Entrevista concedida em março de 2016).
\end{abstract}

Acontece por meio de conversas individuais, algumas vezes coletivas nos planejamentos, resgatando os resultados dos alunos das séries anteriores ao ensino médio para que os professores das turmas de $1^{\circ}$ ano possam ser sabedouros de com quais conhecimentos esses alunos estão chegando à escola (GESTOR. Entrevista concedida em março de 2016).

Ao perguntamos aos professores, o professorP1 respondeuao questionamento, informando que "a escola faz uma reunião com os professores e com toda a equipe da escola”; já o professor P2 discorda e diz que: "Não recebemos nenhuma ajuda de como fazer, os gestores só querem que dê certo e a nota aumente", o que nos revela que a gestão da escola, embora faça reuniões buscando dialogar sobre o processo de apropriação dos resultados e possibilitar a interpretação correta dos dados na busca por melhorias no processo educacional, alguns atores, conforme citado por P2, "não recebem ajuda de como fazer".

Assim, percebemos que a instituição nãovem realizando isso satisfatoriamente, pois, mesmo existindo essas reuniões que abordam a discussão sobre essa temática, elas ocorrem de modo que não contemplam todos os atores escolares; não existe um debate que procure envolver professores e alunos na busca de desenvolver ações coletivas e atitudes compartilhadas entre os docentes para a busca de aperfeiçoamento no ensino-aprendizagem na escola. Ainda, segundo $\mathrm{P} 2$, existe uma cobrança por melhorias, uma responsabilização dos professores pelo aumento sistemático das notas nas avaliações submetidas. 
Quando perguntamos ao coordenador e ao gestor sobre possíveis sugestões para o aprimoramento do processo de apropriação dos resultados na escola, eles disseram que:

A apresentação constante para os professores, a intensificação de mais momentos pedagógicos e, para esse ano, ocorrerão os momentos de convergência nos planejamentos, onde todas as áreas terão um dia específico para planejar na escola, em conjunto, todos os professores das áreas de Humanas, de Ciências da Natureza e Matemática e Linguagens.

Agora como coordenador (num único espaço escolar) poderei estar mais próximo e auxiliando nas apresentações dos projetos, no planejamento dos alunos que nós temos e o que precisamos melhorar. E agora, com o espaço que teremos na escola nova, poderemos planejar em conjunto para uma única escola, em um mesmo espaço geográfico (C1. Entrevista concedida em março de 2016).

Trabalhar continuamente a formação dos professores visando a integração de todos $e$ despertando a corresponsabilidade de toda a equipe escolar (secretaria, professores, gestores, família) no atingimento de melhores resultados. A família também deve participar desse processo, recebendo esclarecimento do que representam essas avaliações, qual a importância da participação dos filhos para o seu respectivo processo de aprendizagem e como ela (a família) pode contribuir fazendo o devido acompanhamento (C2. Entrevista concedida em março de 2016).

Constatamos que os coordenadores estão muito esperançosos, pois, com o novo espaço escolar, as reuniões pedagógicas acontecerão de modo único, sem divisões entre os prédios escolares. Estes poderão acompanhar sistematicamente os planejamentos e, para o ano de 2016, os professores poderão se reunir por áreas de fato, estabelecendo ações que deverão ser associadas entre todos os setores de ensino.

Nas falas dos entrevistados foi salientada também a importância da participação das famílias nesse processo, sendo necessária a criação de espaços para que os familiares possam participar e agir em conjunto com os gestores e professores nas estratégias de melhoria no ensino e aprendizagem. Soares (2004) corrobora dizendo que a participação da família na vida escolar dos filhos acontece por meio da educação de atitudes e valores favoráveis ao ambiente escolar, auxiliando o desempenho dos alunos. Por isso, a escola deve proporcionar que os pais exerçam esse potencial transformador das atitudes familiares na escola, incentivando que as famílias participem e ajudem na instauração de rotinas domésticas favoráveis ao aprendizado.

Nessa mesma pergunta, obtivemos como sugestão do Professor P1 que a apropriação de resultados na escola precisa 
[...] ser melhorada, pois o nosso trabalho é avaliado por essa prova, deve ser intensificado um maior trabalho por todos os professores da escola, e não somente os de português e matemática. Devem ser elaborados projetos, destinar uma aula específica para preparar e conscientizar os alunos para essa avaliação, pois os alunos não possuem consciência da importância da prova, não percebem o retorno que essa avaliação pode trazer para eles, para a escola, para os próprios professores. Devem ter uma preparação até mesmo psicológica para participar das diversas avaliações que na vida poderão enfrentar. Incentivar a participação dos pais, das famílias, pois estas não sabem, então poderia ser divulgado até mesmo na matrícula dos filhos como eles estão na escola (P1. Entrevista concedida em março de 2016).

Identificamos na fala de P1 a necessidade de uma articulação entre todos os professores da instituição escolar, para que em conjunto possam realizar projetos e ações que busquem as melhorias no ensino e na constituição de uma cultura avaliativa na escola.

Ao indagarmos sobre de que maneira as avaliações externas, realizadas na escola, no caso específico do Spaece, auxiliam no seu trabalho como gestor/coordenador escolar, o gestor limitou-se a responder que: “O Spaece está demonstrando a realidade da escola relativa ao processo ensinoaprendizagem"; já C2 compreende de modo mais amplo e sistêmico, pois indica:

Como é uma avaliação diagnóstica em larga escala, ainda que em nível estadual, ela favorece um panorama dos resultados escolares de todas as escolas da rede. Através desse ranking podemos balizar e direcionar melhor o nosso trabalho pedagógico. Facilita muito a nossa análise porque os dados são prontos. Proporciona-nos uma visão panorâmica e, a partir daí, buscaremos eficácia no trabalho desempenhado através de estratégias mais adequadas e eficientes (C2. Entrevista concedida em março de 2016).

O coordenador escolar C2 foi mais específico e detalhou como acontece a apropriação dos resultados pelos professores:

Os coordenadores possibilitam o acesso dos professores aos dados e às informações pertinentes aos resultados de avaliações externas. Proporcionando momentos de discussão, dando apoio pedagógico, sobretudo no acompanhamento do planejamento, sugerindo estratégias de trabalho e material pedagógico, acompanhando os resultados. Reconstruindo metas (C2. Entrevista concedida em março de 2016).

Ao fazer a mesma pergunta para o coordenador $\mathrm{C} 1$, ele demonstrou preocupação com o domínio das informações necessárias para as intervenções pedagógicas serem implantadas pelos professores e os próprios gestores, e efetivamente gerarem uma mudança dos últimos resultados recebidos pela escola. Segundo C1: 
Sinceramente, no momento atual ainda não discutimos como apropriar esses resultados com os professores para o ano letivo de 2016, teremos o planejamento para pensar sobre isso. Muitas vezes planejamos e fica fora da realidade, nossa escola tem baixado os índices $e$ não pouco, talvez pela falta de planejar com os professores estratégias para aumentar esses índices (C1. Entrevista concedida em março de 2016).

Uma sugestão é a própria gestão se apropriar dos resultados com mais carinho e observar a real realidade da escola, e, a partir daí, os professores poderão se apropriar de forma mais rigorosa e segura. É necessário também que a gestão se una para que todos possam se articular com os planejamentos por áreas e ajudem na elaboração de ações para uma melhora nos índices e nos níveis de proficiência da escola (C1. Entrevista concedida em março de 2016).

Ao questionarmos os professores entrevistados sobre como a gestão da escola auxiliava os seus profissionais para que se apropriassem e utilizassem os resultados do Spaece no planejamento das aulas, o professor P1 informou que "a gestão se reúne, onde são repassados como os alunos se saíram nas provas, mas deveria ser mais frequente, ao longo do ano". Enquanto isso, o professor P2 disse que "a gestão fala muito que temos que planejar com 0 foco nos descritores e meu diretor diz inclusive que podemos suspender todo o conteúdo e aplicar somente simulados do Spaece".

Essas informações sugerem que os gestores não estão realizando eficientemente um processo de apropriação dos resultados. Eles deveriam realizar um trabalho de conscientização e mobilização do processo de apropriação de resultados do Spaece, ao longo de todo o período letivo, e eles mesmos estão precisando se atualizar e compreender unissonamente os aspectos relacionados ao reforço de práticas pedagógicas ligadas para a promoção de melhorias nos resultados das avaliações, como é notório na fala do coordenador $\mathrm{C} 1$ e também nos resultados insatisfatórios dos últimos anos expressos pela escola e mostrados anteriormente neste artigo.

Conforme Machado, Miranda e Dusi (2014, p. 3):

Tais apontamentos sinalizam a necessidade de um olhar mais atento para o trabalho desenvolvido pelos gestores; para as habilidades e competências necessárias ao seu bom desempenho; e para a questão da formação para o exercício da gestão escolar, que nem sempre é capaz de desenvolver as competências necessárias ao cargo, principalmente no contexto de maior cobrança da escola por resultados. 
O Plano de Ação Educacional (PAE) que iremos mostrar tem como objetivo contribuir para uma melhor utilização dos resultados das avaliações externas do Spaece, por parte do núcleo gestor (diretor e coordenadores escolares), da comunidade escolar (pais, alunos e servidores) e corpo docente para que possam dialogar constantemente sobre o aperfeiçoamento das práticas desenvolvidas na escola.

O PAE será desenvolvido com base em três ações principais. O primeiro ponto é a criação de uma agenda de encontros e reuniões com o núcleo gestor (diretor geral e coordenadores escolares) e o Professor Coordenador de Ensino (PCE). Esses encontros serão estabelecidos para que a parte pedagógica da escola possa estruturar ações e estudos constantes que possibilitem fortalecer as reflexões sobre o processo de apropriação de resultados, identificar e combater as causas do desempenho insatisfatório nas avaliações externas, e, além disso, estruturar um planejamento estratégico com os direcionamentos e definições dos papéis que cada membro deverá assumir na escola, para que todos possam agir homogeneamente nas ações da escola que visem a melhorar o desempenho da aprendizagem.

Num segundo momento, propomos o desenvolvimento de ações que fortaleçam o projeto político-pedagógico (PPP) da escola, para que pais, alunos, professores e servidores possam elaborar uma proposta curricular mais próxima da realidade social da comunidade, priorizando o vínculo entre a escola, a família e a comunidade; além de favorecer o diálogo constante entre os diversos atores escolares, proporcionar um conhecimento amplo sobre o processo da apropriação dos resultados das avaliações externas e buscar melhorias nas práticas pedagógicas da escola e a aproximação de todos os membros da comunidade escolar (pais, alunos, professores e servidores).

Por fim, propomos estabelecer um processo de formação continuada para os docentes e ações específicas para os professores de matemática, para que estes possam melhorar as suas práticas pedagógicas em sala de aula. Cabe informar que as orientações estabelecidas para a criação das ações propostas nas três etapas se restringem à dimensão escolar e podem ser executadas pela escola por meio da reorganização do trabalho escolar.

Ao ser estabelecida a proposta do Plano de Ação a ser executado na escola pesquisada, compreendemos a importância de acompanhar o seu desenvolvimento. Para o acompanhamento dessa proposta, sugere-se que 
todas essas ações sejam objeto de diálogos nas reuniões de discussão e implantação da primeira ação, ou seja, as reuniões entre os coordenadores escolares, o gestor da escola e o PCE.

Nessas reuniões, deverão ser estabelecidos prazos e metas para que o diretor da unidade escolar, mais os coordenadores escolares, possam cumpri-los. As reuniões deverão acontecer semanalmente. Sugerimos que seja na segundafeira, já que nos outros dias os coordenadores deverão estar à disposição para a formação continuada dos professores, auxiliando e verificando os planejamentos dos docentes.

Além disso, anualmente, deverão ser constituídos, junto com todos os atores escolares (alunos, professores, servidores e pais), durante as reuniões estabelecidas, os pontos fortes e fracos que a escola precisa melhorar, bem como deve ser verificado o desempenho dos alunos a cada ciclo de avaliação externa a que os alunos são submetidos, além de ser necessário verificar também as sugestões que a comunidade escolar poderá ter para a melhora da qualidade da educação na escola.

\section{CONSIDERAÇÕES FINAIS}

Esta pesquisa teve como objetivo investigar as ações de apropriação de resultados pelos gestores da Escola Jabuti e analisar o desempenho discente em matemática. Verificamos como os gestores da escola repassam as informações sobre as avaliações externas, no caso do Spaece, aos professores, pais e alunos; além de pesquisar sobre as práticas docentes adotadas pelos professores de matemática e como eles observam as avaliações de larga escola na escola.

Pelos relatos dos agentes escolares entrevistados, foi possível constatar que para a apropriação dos resultados na Escola Jabuti acontecer mais efetivamente, e para que possa atingir os objetivos propostos desse tipo de avaliação, é necessário que os gestores da escola incentivem e criem mecanismos que envolvam a participação da comunidade escolar (pais, alunos e professores) como um todo, para que esses agentes venham a se inteirar dos resultados da avaliação.

Destacamos ainda que a melhora no desempenho discente nas avaliações externas, no caso do Spaece, perpassa uma mudança das práticas adotadas 
pelos docentes e intervenções da equipe gestora na dimensão pedagógica da gestão escolar. A gestão da escola precisa repensar as práticas administrativas e pedagógicas adotadas. Faz-se urgente dialogar com todos os professores, pais de alunos, servidores e o corpo discente para que a gestão escolar vislumbre melhores resultados, tanto nos processos internos que a escola desenvolve como nos resultados das avaliações externas.

Inferimos que, havendo a conscientização dos problemas a ser enfrentados, a equipe da gestão da Escola Jabuti poderá mobilizar todos os atores, professores, alunos, servidores e os pais dos discentes a encontrarem soluções dentro do contexto que a escola vivencia e necessita para caminhar para uma melhora no desempenho das atividades escolares propostas. 


\section{An investigation on the Appropriation of Mathematics Results in SPAECE: The Case of Escola Jabuti}

Abstract: This article investigated the performance of secondary education students in mathematics at Escola Jabuti, a state school which belongs to the Ceará State education system. The investigation is based on the students' performance in the SPAECE assessment from 2012 to 2014. Our goals were to examine the appropriation of assessment results by the school's management and propose suggestions to deal with the situation, so as to help design an intervention proposal to improve pedagogical monitoring and minimize the mathematics education lag in that school. The question that guided the investigation was: What appropriation actions the school's management has been taking to deal with students' results in SPAECE? The study's final product consisted of an Educational Action Plan (PAE) with suggestions for improving the school's pedagogical practices and the approach of all members of the school community

Keywords: Appropriation of results in mathematics. Assessment. SPAECE. 


\section{Una investigación sobre la apropiación de resultados de matemáticas del Spaece: el caso de la Escuela Jabuti}

Resumen: En este artículo se investigó la situación del desempeño en matemáticas de los alumnos de enseñanza media de la Escuela Jabuti, perteneciente a la red de enseñanza del estado brasileño de Ceará, a partir de los resultados del Sistema Permanente de Evaluación de la Educación Básica en Ceará (Spaece) en los años 2012-2014. Los objetivos definidos para este estudio fueron investigar las acciones de apropiación de resultados por parte de los gestores de la escuela y proponer sugerencias de acciones para la situación analizada, con vistas a contribuir a la elaboración de una propuesta de intervención para mejorar el seguimiento pedagógico y minimizar el desfase de aprendizaje en dicha escuela. La cuestión que guió la investigación fue la siguiente: ¿qué acciones de apropiación ha movilizado la dirección de la escuela ante los resultados del Spaece? Como producto final, se elaboró un plan de acción educativo (PAE) con posibilidades de mejoras en las prácticas pedagógicas de la escuela y la aproximación de todos los miembros de la comunidad escolar.

Palabras clave: Apropiación de resultados en matemáticas. Evaluación. Spaece. 


\section{REFERÊNCIAS}

ALAVARSE, Ocimar Munhoz; de BLASIS, Eloisa; FALSARELLA, Ana Maria. Avaliação e aprendizagem: avaliações externas: perspectivas para a ação pedagógica e gestão do ensino. São Paulo: Cenpec: Fundação Itaú Social, 2013.

BASTOS, Cleverson; KELLER, Vicente. Introdução à metodologia científica. Petrópolis: Vozes, 2007.

BRITO MENEZES, Anna Paula. Contrato didático e transposição didática: interrelações entre os fenômenos didáticos na iniciação à álgebra na 6a série do ensino fundamental. 2006. Tese (Doutorado em Educação)-Faculdade de Educação, Universidade Federal de Pernambuco, Recife, 2006.

CANUTO, Zulma. A emblemática situação do 3ํㅗㄷㅇo em matemática na Rede Municipal de Belo Horizonte: o caso da escola Fernando Dias Costa. 2013. Dissertação (Mestrado profissional)-Programa de Pós-graduação em Gestão e Avaliação da Educação Pública, Faculdade de Educação/Caed, Universidade Federal de Juiz de Fora, Juiz de Fora, 2013.

CEARÁ. Decreto n. 21.398, de 31 de maio de 1991. Dispõe sobre a finalidade, estrutura organizacional, redistribuição dos cargos de direção e assessoramento da Secretaria da Educação. Diário Oficial do Estado, Fortaleza, CE, 31 maio 1991.

Portaria n. 101/00 - GAB de 15 de fevereiro de 2000. Dispõe sobre a Instituição do Sistema Permanente de Avaliação da Educação Básica do Ceará - Spaece. Diário Oficial do Estado, Fortaleza, CE, 17 fev. 2000.

Secretaria da Educação Básica do Ceará. Centro de Políticas Públicas e Avaliação da Educação - Caed. Spaece 2000. Boletim Pedagógico de Avaliação: Matemática, Ensino Médio. Universidade Federal de Juiz de Fora, Faculdade de Educação, Caed, Juiz de Fora, v. 1, jan./dez. 2008. Disponível em: 〈http://www.spaece.caedufjf.net/colecao/2008-2/〉. Acesso em: 10 ago. 2015.

- Secretaria da Educação Básica do Ceará. Centro de Políticas Públicas e Avaliação da Educação - Caed. Spaece 2014. Boletim do Gestor. Juiz de Fora, 2015. Disponível em: 〈http://www.spaece.caedufjf.net/colecao/ boletins-2014/>. Acesso em: 10 set. 2015. 
D’AMBROSIO, Ubiratan. Etnomatemática: elo entre as tradições e a modernidade. Belo Horizonte: Autêntica, 2009.

FREITAS, Pamela Felix. Usos das avaliações externas: concepções de equipes gestoras de escolas da rede municipal de ensino de São Paulo. 2014. Dissertação (Mestrado)-Programa de Pós-graduação em Educação Faculdade de Educação, Universidade de São Paulo, São Paulo, 2014.

GIL, Antonio Carlos. Como elaborar projetos de pesquisa. 4. ed. São Paulo: Atlas, 2008.

HIPPOLYTO, Luzia de Queiroz. Avaliação dos resultados do Spaece da $3^{a}$ série do ensino médio, em matemática, no Ceará, e sua repercussão na prática pedagógica dos professores: um estudo descritivo dos anos 2008, 2009 e 2010. 2013. 157 f. Dissertação (Mestrado profissional)-Centro de Ciências, Programa de Pós-graduação em Ensino de Ciências e Matemática, Universidade Federal do Ceará, Fortaleza, 2013.

LIMA, Costa Alessio. O Sistema Permanente de Avaliação da Educação Básica do Ceará (Spaece) como expressão da política pública de avaliação educacional do estado. 2007. Dissertação (Mestrado)-Universidade Estadual do Ceará, Fortaleza, 2007.

LORENZATO, Sérgio. Para aprender matemática. Campinas: Autores Associados, 2006. 138 p.

LÜCK, Heloísa. Perspectivas da gestão escolar e implicações quanto à formação de seus gestores. Em Aberto, Brasília, v. 17, n. 72, p. 11-33, 2000.

- Dimensões da gestão escolar e suas competências. Curitiba: Positivo, 2009.

MACHADO, Cristiane. Avaliação externa e gestão escolar: reflexões sobre usos dos resultados. Revista @mbienteeducação, p. 70-82, jan./jun. 2012. ISSN 1982-8632. Disponível em: 〈http://arquivos.cruzeirodosuleducacional.edu. br/principal/old/revista_educacao/pdf/volume_5_1/educacao_01_70-82. pdf〉. Acesso em: 21 ago. 2015.

MACHADO, Márcia Cristina da Silva; MIRANDA, Josélia Barbosa; DUSI, Sayuri Côrtes Ouchi. A gestão escolar e os desafios de melhoria no desempenho educacional: uma reflexão a partir do caso da rede pública municipal de 
ensino de Juiz de Fora - MG. 2014. Disponível em: 〈http://www.anpae.org. br/simposio26/1comunicacoes/MarciaMachado-ComunicacaoOral-int.pdf . Acesso em: 20 out. 2015.

MUNIZ, Cristiano Alberto. Pedagogia: educação e linguagem matemática. Brasília: Fundação Universidade de Brasília, 2010.

PAZ, Fábio Mariano; RAPHAEL, Hélia Sônia. O Ideb e a qualidade da educação no ensino fundamental: fundamentos, problemas e primeiras análises comparativas. Omnia Humanas, v. 3, n. 1, p. 7-30, 2010.

ROCHA, Creusa Coelho da Silva. Análise do baixo desempenho em matemática dos alunos do 6ำ ano do ensino fundamental da Escola Estadual Getúlio Vargas (Belo Horizonte - MG). 2014. Dissertação (Mestrado acadêmico)-Programa de Pós-Graduação em Educação, Faculdade de Educação/CAEd, Universidade Federal de Juiz de Fora, Juiz de Fora, 2014.

SAVIANI, Dermeval. O plano de desenvolvimento da educação: análise do projeto do MEC. Educação Sociedade Campinas, v. 28, n. 100 - Especial, p. 1231-1255, out. 2007. Disponível em: 〈http://cedes.preface.com.br/〉. Acesso em: 20 out. 2015 .

SILVA, Roberto Claudio Bento da. Apropriação dos resultados do Spaece pelos gestores escolares: um estudo de caso envolvendo duas escolas do interior do Ceará. 2014. Dissertação (Mestrado profissional)-Programa de Pósgraduação em Educação, Faculdade de Educação/Caed, Universidade Federal de Juiz de Fora, Juiz de Fora, 2014.

SOARES, J. F. Fatores associados ao desempenho em língua portuguesa e matemática: a evidência do Saeb 2001. Relatório de Pesquisa. Belo Horizonte: UFMG, 2004.

SOUSA, Sandra Zákia; OLIVEIRA, Romualdo Portela. Sistemas estaduais de avaliação: uso dos resultados, implicações e tendências. Cadernos de Pesquisa, v. 40, n. 141, p. 793-822, 2010. Disponível em: 〈http://producao. usp.br/handle/BDPI/6411〉. Acesso em: 20 ago. 2015.

VIEIRA, Sofia Lerche. Gestão, avaliação e sucesso escolar: recortes da trajetória cearense. Estudos Avançados, v. 21, n. 60, p. 45-60, 2007. Disponível em: 〈http://www.revistas.usp.br/eav/article/view/10236/11853〉. Acesso em: 10 out. 2015. 
YIN, Robert K. Estudo de caso: planejamento e métodos. 2. ed. Porto Alegre: Bookman, 2001.

SOBRE OS AUTORES

Francisco Jucivanio Felix de Sousa é mestre em Educação pela Universidade Federal de Juiz de Fora. Atualmente é professor do Instituto Federal do Ceará (IFCE), campus Crateús.

E-mail: jucivanio.felix@ifce.edu.br.

Marco Aurélio Kistemann Jr. é doutor em Educação Matemática pela Universidade Estadual Paulista (Unesp). Atualmente é professor do Departamento de Matemática da Universidade Federal de Juiz de Fora (UFJF).

E-mail: marco.kistemann@ufjf.edu.br.

Recebido em: abril de 2018

Aprovado em: maio de 2018 